\title{
Long and short range order structural analysis of In-situ formed biphasic calcium phosphates
}

\author{
Dong-Hyun Kim', Kyu-Hong Hwang ${ }^{2}$, Ju Dong Lee ${ }^{3}$, Hong-Chae Park and Seog-Young Yoon ${ }^{1 *}$
}

\begin{abstract}
Background: Biphasic calcium phosphates (BCP) have attracted considerable attention as a bone graft substitute. In this study, BCP were prepared by aqueous co-precipitation and calcination method. The crystal phases of in-situ formed BCP consisting of hydroxyapatite (HAp) and $\beta$-tricalcium phosphate ( $\beta$-TCP) were controlled by the degree of calcium deficiency of precursors. The long and short range order structures of biphasic mixtures was investigated using Rietveld refinement technique and high resolution Raman spectroscopy. The refined structural parameters of in-situ formed BCP confirmed that all the investigated structures have crystallized in the corresponding hexagonal (space group P63/m) and rhombohedral (space group R3c) structures.

Results: The crystal phases, Ca/P molar ratio, and lattice parameters of in-situ formed BCP consisting of HAp and $\beta$-TCP were controlled by the degree of calcium deficiency of calcium phosphate precursors. The significant short range order structural change of BCP was determined by Raman analysis.
\end{abstract}

Conclusions: The long and short range order structural changes of in-situ formed BCP might be due to the coexistence of $\beta$-TCP and HAp crystal phases.

Keywords: Biphasic calcium phosphate, Rietveld refinement, Raman spectroscopy

\section{Background}

Biphasic calcium phosphates (BCP) have attracted considerable attention as a bone graft substitute [1-4]. Generally, BCP consisting of biocompatible hydroxyapatite (HAp) and biodegradable $\beta$-tricalcium phosphate $(\beta$-TCP) have better bio-resorbability and osseointegration than the individual HAp or $\beta$-TCP components because of their different dissolution behaviors under in vitro and in vivo biological conditions $[5,6]$.

Several researchers have recently attempted to develop BCP comprising HAp and $\beta-\mathrm{TCP}$ as well using various synthetic routes, such as the blending of different calcium phosphates in solid state reactions, precipitation, liquid mix techniques, treatment of natural bone, spray pyrolysis, and microwave and combustion processing [7-12]. For examples, BCP are usually produced either by the mechanical mixing and sintering of monophasic HAp/ $\beta$-TCP powder mixtures

\footnotetext{
*Correspondence: syy3@pusan.ac.kr

'School of Materials Science and Engineering, Pusan National University, Busan 609-735, Republic of Korea

Full list of author information is available at the end of the article
}

(i.e., ex-situ formation) or by calcining of a single phase calcium deficient hydroxyapatite (CDHA) powders (i.e., in-situ formation). In the case of CDHA, It is well known that BCP and bi-phases can be obtained and controlled through in-situ process of heating CDHA $(\mathrm{Ca} / \mathrm{P}=1.5 \sim 1.67)$ above $700{ }^{\circ} \mathrm{C}$ according to the Equation (1):

$$
\begin{gathered}
\mathrm{Ca}_{10-\mathrm{x}}\left(\mathrm{HPO}_{4}\right)_{\mathrm{x}}\left(\mathrm{PO}_{4}\right)_{6-\mathrm{x}}(\mathrm{OH})_{2-\mathrm{x}}=(1-\times) \mathrm{Ca}_{10}\left(\mathrm{PO}_{4}\right)_{6}(\mathrm{OH})_{2} \\
+3 \times \mathrm{Ca}_{3}\left(\mathrm{PO}_{4}\right)+\mathrm{xH}_{2} \mathrm{O}
\end{gathered}
$$

In addition, the in-situ formation method of BCP can be also applied to various studies of ionic substitutions, biopolymer/calcium phosphate composites, local drug delivery system, and porous scaffolds [13-16]. Because the studies of various attempts for BCP still need to be focused in order to optimize the biological performances. Consequently, fundamental efforts to improve the biological response of in-situ formed BCP have recently based on studies of various biphasic controls of HAp/TCP ratios. 
The research for crystal structure of in-situ formed $\mathrm{BCP}$ has been the subject of specific interest owing to its essential biological role in the comprehension for coexistence of two crystal phases. Despite having the similar elemental composition, HAp $\left(\mathrm{Ca}_{10}\left(\mathrm{PO}_{4}\right)_{6}(\mathrm{OH})_{2}\right)$ and $\beta$ TCP $\left(\mathrm{Ca}_{3}\left(\mathrm{PO}_{4}\right)_{2}\right)$ differ considerably in their crystal system. For example, crystal system of $\beta$-TCP has generally a rhombohedral (space group R3c) or hexagonal structure (space group R3c). HAp has a hexagonal (space group $\mathrm{P} 63 / \mathrm{m}$ ) or monoclinic structure (space group P21/b). Such different crystallographic forms of HAp and $\beta$-TCP can be performed the different biological properties related to biodegradation and dissolution rate. Therefore, if a crystal system of BCP can be controlled and varied by in-situ formed bi-phases, it can suggest a new paradigm of bioceramic applications for improve biological properties. In this study, the ability to clearly identify an individual crystal structure of in-situ formed $\mathrm{BCP}$ demonstrate in the long and short range order structural analysis using the Rietveld refinement of X-ray diffraction (XRD) spectra and high resolution Raman spectroscopy.

\section{Methods}

$\beta$-TCP, HAp, and BCP powders were synthesized by the co-precipitation and calcination process. Firstly, an appropriate amount $(\mathrm{Ca} / \mathrm{P}$ molar ratio $1.5 \sim 1.67)$ of calcium nitrate tetrahydrate $\left(\mathrm{Ca}\left(\mathrm{NO}_{3}\right)_{2}{ }^{\circ} 4 \mathrm{H}_{2} \mathrm{O}\right.$, SigmaAldrich) and diammonium hydrogen phosphate $\left(\left(\mathrm{NH}_{4}\right)_{2} \cdot \mathrm{HPO}_{4}\right.$, Sigma-Aldrich $)$ was dissolved in distilled water by vigorously stirring at a rate of $1000 \mathrm{rpm}$. The $\mathrm{pH}$ of the mixed solution was maintained at 8 and 11 by the addition of ammonium hydroxide $\left(\mathrm{NH}_{4} \mathrm{OH}\right.$, Junsei) solution. The co-precipitated suspension was discharged from the reactor and allowed to settle for $24 \mathrm{~h}$ for the maturation of precipitate. After $24 \mathrm{~h}$, the precipitates were separated through vacuum filtration technique and dried at $80{ }^{\circ} \mathrm{C}$ for $24 \mathrm{~h}$ in a drying oven. The as-dried precipitates were calcined at $1000^{\circ} \mathrm{C}$ for $24 \mathrm{~h}$ in air.

X-ray diffraction analysis (X'Pert Pro, Philips), at $40 \mathrm{kV}$ and $40 \mathrm{~mA}$ with a scanning speed of $1 \mathrm{o} / \mathrm{min}$, was performed to identify the phases of the as-calcined powders. A standard Bragg-Brentano geometry was applied with a $\mathrm{K}_{\alpha} 1$ monochromatic beam from the $\mathrm{Cu}$ anode. Phase identification, quantitative analysis, determination of $\mathrm{Ca} / \mathrm{P}$ ratio, and lattice parameters for the $\mathrm{BCP}$ powders were characterized using Phillips X'Pert HighScore Plus software with a full-pattern fit using Rietveld method $[17,18]$. The Raman spectra were recorded on a Sentinel Raman spectrometer (Bruker Optics Ltd.) with a Unilab II probe (fiber optic) and a CCD detector was used in this study. A $532 \mathrm{~nm} \mathrm{Nd:} \mathrm{YAG} \mathrm{laser} \mathrm{source} \mathrm{was}$ used for excitation with an incident laser power of $30 \mathrm{~mW}$. The spectral range was 500 to $4400 \mathrm{~cm}^{-1}$ with a resolution of 4 to $6 \mathrm{~cm}^{-1}$.

\section{Results and discussion}

Figure 1 shows Rietveld analysis, determined crystal phase $\%$, and calculated $\mathrm{Ca} / \mathrm{P}$ ratio for as-synthesized $\beta$ TCP, HAp, and BCP powders. Figure 1(a) shows fitting deviations of XRD patterns of $\beta$-TCP, HAp, and BCP powders with Rietveld analysis. Pattern fitting was carried out between 10 and $70^{\circ}$. As shown in Fig. 1(a), Rietveld refinement was performed using the structural model of ICSD card number \# 6191 and 97500 for $\beta$-TCP phase. The structural model of ICSD card number \# 26205 and 87670 were used for HAp phase. Figure 1(b) shows the percentage of relative determined crystal phase and calculated $\mathrm{Ca} / \mathrm{P}$ ratio of the $\beta$-TCP, HAp, and BCP powders through Rietveld analysis. (a)

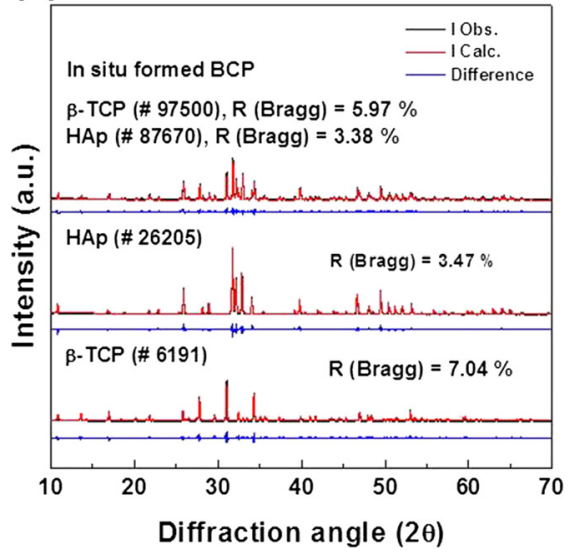

(b)

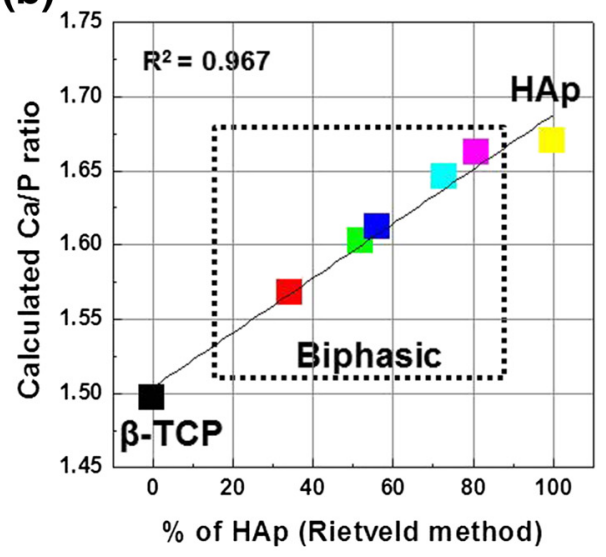

Fig. 1 a Rietveld analysis patterns of powder diffraction data of BCP and $\mathbf{b}$ molar Ca/P ratio of BCP calculated using Rietveld method 
(a)

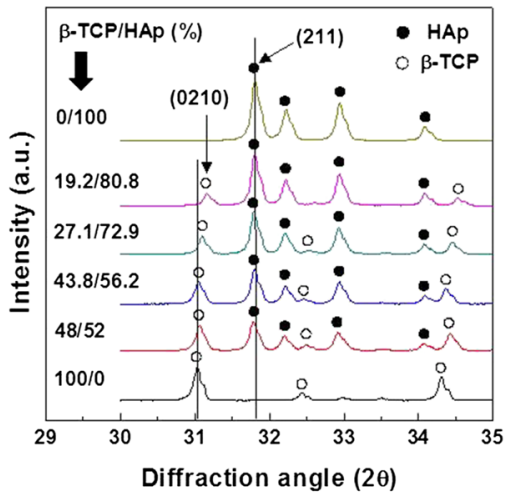

(b)

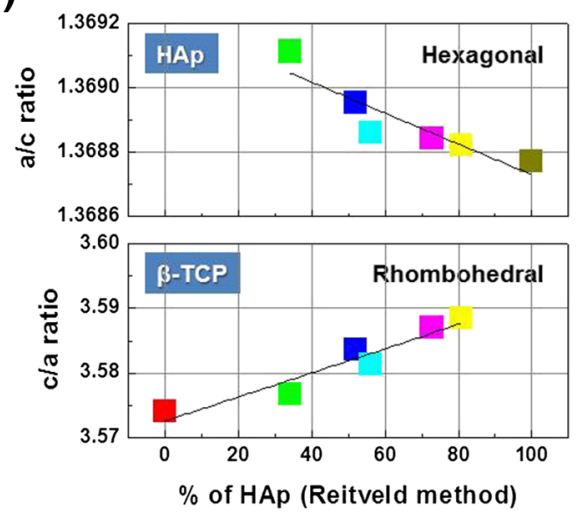

(c)

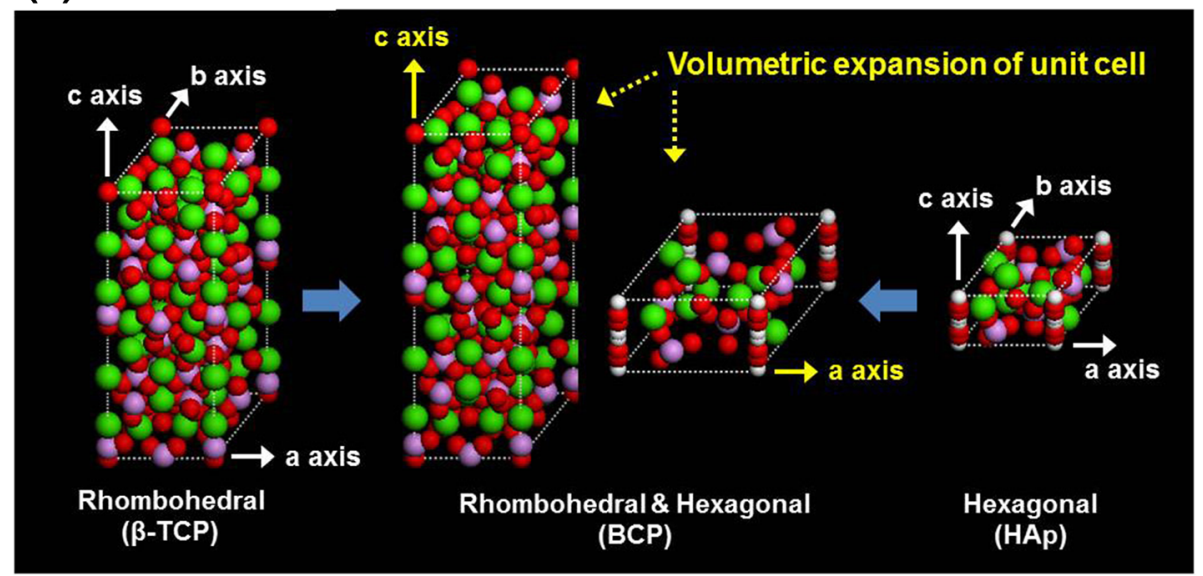

Fig. 2 a XRD patterns, $\mathbf{b}$ axial ratio, and $\mathbf{c}$ volumetric expansion behavior of unit cells of in-situ formed BCP. (Note: axis of $\beta$-TCP and HAp is $a=b$ and axial angle is $a=\beta=90^{\circ}, \gamma=120^{\circ}$ )

(a)

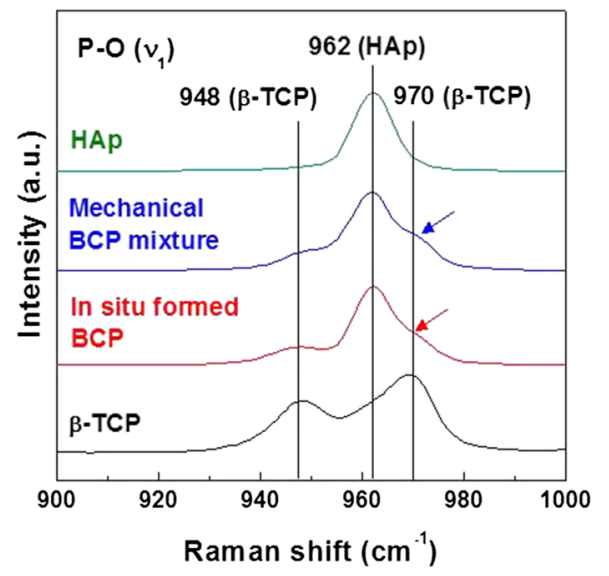

(b)

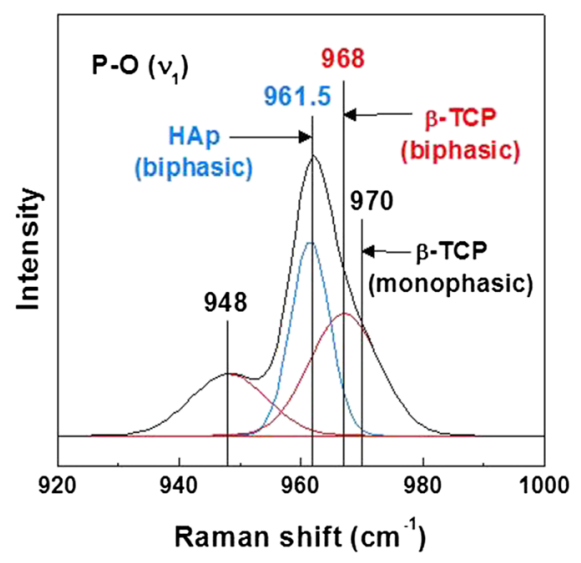

Fig. 3 a Symmetric vibration (stretching mode, $v_{1}$ ) of $\mathrm{PO}_{3}^{4-}$ of $\beta-T C P, H A p$, mechanical mixed BCP, and in-situ formed BCP and $\mathbf{b}$ pseudo Gaussian fitting results from Raman spectra of in-situ formed BCP 
An attempt was also made to determine the reliability of the resultant phase mixtures obtained through refinement with those of experimental $\mathrm{Ca} / \mathrm{P}$ ratio of the precursors according to Equation (2):

$$
\begin{aligned}
\text { Expected } \mathrm{Ca} / \mathrm{P}= & \text { wt } \% \text { of } \mathrm{HAp}(\text { Rietveld }) * 1.67 \\
& + \text { wt } \% \text { of TCP }(\text { Rietveld }) * 1.5
\end{aligned}
$$

As shown in Fig. 1(b), BCP powders have indicated only the presence of HAp and $\beta$-TCP in its composition but their quantitative phase contents determined through Rietveld analysis were found to show significant variations, and their $\mathrm{Ca} / \mathrm{P}$ ratio were totally dependent on the percentage of determined crystal phase.

Figure 2 shows biphasic behaviors and effects of crystal system of in situ formed BCP with different phase contents. The expanded XRD patterns of BCP in the close scan around the main peak region $\left(2 \theta=30-35^{\circ}\right)$ as shown in Fig. 2(a). The $\beta$-TCP (0210) peak is well distinguished and differentiated from the HAp (211) peak. Figure 2(b) shows axis ratio of $\beta$-TCP and HAp phase in the lattice parameters of in-situ formed BCP with different phase contents. In the case of in-situ formed BCP, the as-calculated $c / a$ axis ratio of $\beta$-TCP phase was increased with increasing HAp phase contents as shown in Fig. 2(b). On the other hand, the $a / c$ axis ratio of HAp showed a little decrease to closed a/c ratio of monophasic HAp. In contrast to result of $\beta$-TCP, the ascalculated a/c axis ratio of HAp phase of in-situ formed $\mathrm{BCP}$ was decreased to the theoretical a/c axis ratio $(\mathrm{a} / \mathrm{c}$ ratio $=1.3689$, ICSD \# 87670). In addition, a volume for unit cell of in-situ formed BCP showed the volumetric expansion, compared to the monophasic HAp and $\beta$-TCP, as shown in Fig. 2(c).

Figure 3 shows the short range order structural analysis of in-situ formed BCP. Figure 3(a) shows the Raman spectra of $\beta$-TCP, HAp, mechanical mixed BCP, and in-situ formed BCP, assigned to a symmetric P-O vibration (stretching mode, $v_{1}$ ) within the $\mathrm{PO}_{3}^{4-}$ group. Among the spectra shown in Fig. 3(a), it is spectrum of the in-situ formed BCP that is most similar to spectra observed from mixture of pure $\beta$-TCP and HAp. However, it is evident that $\mathrm{P}-\mathrm{O}$ vibration peak (i.e., $968 \mathrm{~cm}^{-1}$ of $\beta$-TCP) of in-situ formed BCP (i.e., $43.8 \%$ of $\beta$-TCP and $56.2 \%$ of HAp determined by Rietveld analysis) indicated a peak shift, compared with monophasic $\beta$-TCP and mechanical mixed BCP (i.e., $44 \%$ of $\beta$-TCP and $56 \%$ of HAp), as shown in Fig. 3(b). Therefore, the short range order structure of in-situ formed BCP could be considered to be affected by the coexistence of $\beta$-TCP and HAp phase.

\section{Conclusions}

HAp, $\beta$-TCP and in situ formed BCP powders were synthesized by the co-precipitation and calcination process. The refined structural parameters of in-situ formed BCP confirmed that all the investigated structures have crystallized in the corresponding hexagonal (space group $\mathrm{P} 63 / \mathrm{m}$ ) and rhombohedral (space group R3c) structures. The molar $\mathrm{Ca} / \mathrm{P}$ ratio of in-situ formed BCP was also determined by Rietveld analysis. The crystal phases, $\mathrm{Ca} / \mathrm{P}$ molar ratio, and lattice parameter of in-situ formed BCP consisting of HAp and $\beta$-TCP were controlled by the degree of calcium deficiency of calcium phosphate precursors. The significant short range order structural change of BCP was determined by Raman analysis. The short range order structures of in-situ formed BCP was considered to be affected by the coexistence of $\beta$-TCP and HAp phase.

\section{Availability of supporting data}

The data set supporting the results of this article is included within the article Tables 1, 2, 3, 4 are represented structure model of HAp and $\beta$-TCP crystal in XRD results of this study (Additional file 1).

\section{Additional file}

Additional file 1: Table S1. Structure model of HAp (ICSD card number: \# 26205). Table S2. Structure model ofHAp (ICSD card number: \# 87670). Table S3. Structure model of $\beta$-TCP (ICSD card number: \# 6191). Table S4. Structure model of $\beta$-TCP (ICSD card number: \# 97500).

\section{Competing interests}

The authors declare that they have no competing interests.

\section{Authors' contributions}

DHK and SYY designed the experiments, carried out crystal structure analysis of biphasic calcium phosphates by Rietveld refinement and drafted the manuscript. JDL participated in the design of the study and carried out Raman analysis. $\mathrm{KHH}$ and HCP conceived of the study, and participated in its design and coordination and helped to draft the manuscript. All authors read and approved the final manuscript.

\section{Acknowledgment}

This research was supported by Basic Science Research Program through the National Research Foundation of Korea (NRF) funded by the Ministry of Education, Science and Technology (No. 2013R1A1A4A01009089). This work was also supported by Korea Institute of Industrial Technology.

\section{Author details}

${ }^{1}$ School of Materials Science and Engineering, Pusan National University, Busan 609-735, Republic of Korea. ${ }^{2}$ School of Nano and Advanced Materials, Gyeongsang National University, Jinju, Gyeongnam 660-701, Republic of Korea. ${ }^{3}$ Korea Institute of Industrial Technology, Busan 618-230, Republic of Korea.

Received: 4 March 2015 Accepted: 9 May 2015

Published online: 31 December 2015

\section{References}

1. De Groot K. Clinical applications of calcium phosphate biomaterials: a review. Ceram Int. 1993;19:363-6. 
2. Jarcho M. Biomaterial aspects of calcium phosphates. Dent Clin North Am. 1986;30:25-47.

3. Bucholz RW, Carlton A, Holmes RE. Hydroxyapatite and tricalcium phosphate bone graft substitutes. Orthop Clin North Am. 1987;18:323-34.

4. Hench LL, Am J. Bioceramics. Ceram Soc. 1998;81:1705-28.

5. Klein CPAT, Driessen AA, De Groot K, van den Hooff A, Biomed J. Biodegradation behaviour of various calcium phosphate materials in bone tissue. Mater Res A. 1983;17:769-84.

6. Dorozhkin SV, Epple M. Biological and Medical Significance of Calcium Phosphates. Angew Chem Int Ed. 2002;41:3130-46.

7. Yamada S, Heyman D, Bouler JM, Daculsi G. Osteoclastic resorption of calcium phosphate ceramics with different hydroxyapatite/ $\beta$-tricalcium phosphate ratios. Biomaterials. 1997;18:1037-41.

8. Bouler JM, LeGeros RZ, Daculsi G, Biomed J. Biphasic calcium phosphates: influence of three synthesis parameters on the HA/ $\beta$-TCP ratio. Mater Res A. 2000;51:680-4.

9. Jarcho M. Calcium phosphate ceramics as hard tissue prosthetics. Clin Orthop Relat Res. 1981;157:259-78.

10. Pena J, Vallet-Regi M, Euro J. Hydroxyapatite, tricalcium phosphate and biphasic materials prepared by a liquid mix technique. Ceram Soc. 2003;23:1687-96.

11. LeGeros RZ, Lin S, Rohanizadeh R, Mijares D, LeGeros JP. Biphasic calcium phosphate bioceramics: preparation, properties and applications. Mater Sci Mater Med. 2003;14:201-9.

12. Vallet-Regi M. Ceramics for medical applications. J Chem Soc Dalton Trans. 2001;97-108.

13. Chang BS, Lee CK, Hong KS, Youn HJ, Ryu HS, Chung SS, et al. Osteoconduction at porous hydroxyapatite with various pore configurations. Biomaterials. 2000;21:1291-8.

14. Santos C, Martins MA, Franke RP, Almeida MM, Costa MEV. Calcium phosphate granules for use as a 5-Fluorouracil delivery system. Ceram Int. 2009;35:1587-94.

15. Nihouannen $D L$, Guehennec $L L$, Rouillon T, Pilet $P$, Bilban $M$, Layrolle $P$, et al. Micro-architecture of calcium phosphate granules and fibrin glue composites for bone tissue engineering. Biomaterials. 2006;27:2716-22.

16. Kamitakahara M, Imai R, loku K. Preparation and evaluation of spherical Ca-deficient hydroxyapatite granules with controlled surface microstructure as drug carriers. Mater Sci Eng C. 2013;33:2446-50.

17. Kim DH, Chun HH, Lee JD, Yoon SY. Evaluation of phase transformation behavior in biphasic calcium phosphate with controlled spherical micro-granule architecture. Ceram Int. 2014;40:5145-55.

18. Kim DH, Park SS, Lee JD, Park HC, Yoon SY. Phase transformation behavior of spherical tricalcium phosphate micro-granules prepared by a jet wheel impact atomization and calcination process. Powder Technol. 2014;257:74-82.

\section{Submit your next manuscript to BioMed Central and take full advantage of:}

- Convenient online submission

- Thorough peer review

- No space constraints or color figure charges

- Immediate publication on acceptance

- Inclusion in PubMed, CAS, Scopus and Google Scholar

- Research which is freely available for redistribution 